\title{
Synthesis of Geopolymer from Coal Fly Ash
}

\author{
Vinay Kumar Jha* and Gautam Prasad Budhamagar \\ Central Department of Chemistry, Tribhuvan University, Kirtipur, Kathmandu, Nepal \\ E-mail: vinayj2@yahoo.com
}

\begin{abstract}
In the present work, geopolymers have been synthesized from coal fly ash (CFA) using $\mathrm{NaOH}$ and $\mathrm{Na}_{2} \mathrm{SiO}_{3}$ as activators. Some parameters like alkali concentration, amount of $\mathrm{Na}_{2} \mathrm{SiO}_{3}$ and curing time have been varied in order to improve the quality of geopolymeric product. The geopolymerization process has been performed using 3-8M NaOH solutions, $\mathrm{Na}_{2} \mathrm{SiO}_{3}$ to $\mathrm{CFA}$ mass ratios of 0.25-1.25 and curing time variation from 5-15 days. The curing temperature was fixed at $40^{\circ} \mathrm{C}$ in all cases. In the variation of $\mathrm{NaOH}$ concentration, the maximum compressive strength of $2.3 \mathrm{MPa}$ was obtained with CFA treated with $6 \mathrm{M} \mathrm{NaOH}$ solution. Similarly during the variation of amount of $\mathrm{Na}_{2} \mathrm{SiO}_{3}$, the maximum compressive strength of $17.6 \mathrm{MPa}$ was obtained with $\mathrm{Na}_{2} \mathrm{SiO}_{3}$ to $\mathrm{CFA}$ mass ratio of 1.25 . Furthermore, the compressive strength was found increasing up to $20.3 \mathrm{MPa}$ with increasing curing time.
\end{abstract}

Keywords: Coal fly ash, Compressive strength, Curing time, Geopolymer, Geopolymerization.

\section{Introduction}

Coal fly ash is one of the residues generated in the combustion of coal. Due to rapid urbanization in Kathmandu valley, a huge amount of coal has been used as fuel. It typically comprises fine, powdery particles that are predominantly spherical, solid or hollow and mostly amorphous (glassy). The chemical properties of CFA are greatly influenced by the chemical content of the coal burned1. Most of CFA is used in construction-related applications such as cement and concrete manufacturing, production of bricks and lightweight aggregates, and as additives for ceramics.

There is a high rate of cement consumption due to the rapid rate of building constructions. The industrial production of cement has two major disadvantages namely the increase in environmental pollution and global warming as the production of 1 ton of Portland cement produces approximately 1 ton of $\mathrm{CO} 2$ and the high energy consumption during the manufacture of cement as it involves a very high temperature $\left(1600^{\circ} \mathrm{C}\right)$. Thus we are facing two severe problems at present stage. The first one is the huge amount of CFA waste and the second one is the atmospheric pollution. Hence, if it is possible to prepare geopolymers of reasonable compressive strengths with CFA waste, it can become a suitable alternative for minimizing the waste as well as for reducing the atmospheric pollution.

The name geopolymer was first applied to the synthetic aluminosilicate materials by a French materials scientist Joseph Davidovits in 19702, although similar materials had been developed in the former Soviet Union since 1950, originally under the name "soil cements"3-6. Geopolymers are amorphous to semi-crystalline three-dimensional aluminosilicate polymers with a chemical composition resembling that of a zeolite. The main properties of geopolymers are quick compressive strength

\footnotetext{
* Corresponding author
} 
development, low permeability, greater chemical and thermal resistance, better mechanical properties at both ambient and extreme conditions and tendency to drastically decrease the mobility of most heavy metal ions contained within the geopolymeric structure5. The potential applications of geopolymers are as a replacement for Portland cement, for advanced high-tech composites, and as immobilization systems for heavy-metals containment.

The 15 samples of combustion fly ashes were tested for their suitability in geopolymeric cements. The samples were cured at room temperature and the compressive strength was measured after 28 days. A large variation was noticed in the behavior of the fly ashes ranging from unworkable situations to strength of $95 \mathrm{MPa}$. A synthesized geopolymers attain compressive strength values of about $60 \mathrm{MPa}$ from coal combustion fly ashes having glass content higher than $90 \%$. The geopolymers were synthesized using $12 \mathrm{M} \mathrm{NaOH}$ and by curing at $80^{\circ} \mathrm{C}$ for $48 \mathrm{hrs} 8$. The compressive strength of geopolymers synthesized from coarse lignite high calcium fly ash was in the range of 10-65 MPa. The optimum sodium silicate to $\mathrm{NaOH}$ ratio was found to be $0.67-1.0$ and curing was performed at the optimum curing temperature of $75^{\circ} \mathrm{C}$ for not less than 2 days 9 . Geopolymers were synthesized from fly ash (FA) and rice husk ash and the compressive strength was obtained in the range of 12.5-56 MPa10.

The present work is the preliminary investigation on the possibility of utilizing coal fly ash as raw materials in the production of geopolymer cement in order to find out the amicable solution for such problem.

\section{Experimental Methods}

\section{Sample Preparation}

The CFA used in this study was obtained from Uma-Maheshwor Itta Udyog of Kirtipur, Kathmandu. The CFA was ground manually by using mortar and pestle to obtain in fine powder form. The powder was then modified chemically by treating with $\mathrm{NaOH}$ solutions (Qualigens chemicals, India) of various concentrations at room temperature. The solid sample was separated from solution by filtration and washed with distilled water for several times till the effluent became neutral to $\mathrm{pH}$ paper and then dried in oven (N6c, Philip Harris, England) at $80^{\circ} \mathrm{C}$ for $4 \mathrm{hrs}$.

\section{Preparation of CFA based geopolymer}

To synthesize geopolymer from CFA, several parameters such as alkali concentration, amount of sodium silicate and curing time were taken into account.

\section{Variation of $\mathrm{NaOH}$ concentration}

In first step, each of the $\mathrm{NaOH}$ treated CFA samples were blended manually for 2 minutes with a single $\mathrm{NaOH}$ concentration using mortar and pestle. The blended mixtures were separately placed in plastic moulds, sealed with thin plastic films and allowed to cure for $4 \mathrm{hrs}$. in oven at $40^{\circ} \mathrm{C}$. After curing, the samples were demoulded and the area of each sample was measured prior to the strength measurement. The compressive strengths of the samples were measured using MARUTO testing machine (s56A, Japan). From this step, the most appropriate concentration of $\mathrm{NaOH}$ solution to be used with varying amount of $\mathrm{Na} 2 \mathrm{SiO} 3$ in the next step was determined.

\section{Variation of amount of sodium silicate}

In second step, the CFA previously treated with $6 \mathrm{M} \mathrm{NaOH}$ solution was blended manually with $6 \mathrm{M}$ $\mathrm{NaOH}$ solution and with the varying amount of $\mathrm{Na} 2 \mathrm{SiO} 3$ (sd fine chemicals, India) using mortar and pestle. The blended mixtures were separately placed in plastic moulds, sealed with thin plastic films and allowed to cure for 6 days in oven at $40^{\circ} \mathrm{C}$. After curing, the samples were demoulded and the area of each sample was measured prior to the strength measurement. Then the compressive strengths of the 
samples were measured as before. From this step, the most appropriate mass ratio of $\mathrm{Na} 2 \mathrm{SiO} 3$ to CFA to be used for curing time variation in the next step was determined.

\section{Variation of curing time}

In third step, $\mathrm{Na} 2 \mathrm{SiO} 3$ to $\mathrm{CFA}$ (previously treated with $6 \mathrm{M} \mathrm{NaOH}$ solution) mass ratio of 1.25 was blended manually with the $6 \mathrm{M} \mathrm{NaOH}$ solution using mortar and pestle. The blended mixtures were separately placed in plastic moulds, sealed with thin plastic films and allowed to cure for 5-15 days in oven at $40^{\circ} \mathrm{C}$. After curing, the samples were demoulded and the area of each sample was measured prior to the strength measurement. Then the compressive strengths of the samples were measured as before. From this step, the variation of compressive strength with curing time was observed.

The air bubbles were removed with the help of ultrasonicator (Bransonic, USA). After $4 \mathrm{hrs}$ curing at $40^{\circ} \mathrm{C}$ in oven, the samples were demoulded. The top face of the sample was made parallel to the bottom and area of the sample was measured. The compressive strength of the sample was measured using Maruto Testing Machine (s56A, Japan).

\section{Results and Discussion}

\section{Characterization of waste}

The LOI of the CFA used in this research work was found to be $9 \%$. Thus according to a report, the type of CFA is expected to be bituminous which is rich in $\mathrm{SiO}_{2}, \mathrm{Al}_{2} \mathrm{O}_{3}$ and $\mathrm{Fe}_{2} \mathrm{O}_{3}$ contents1.

\section{Compressive Strength and $\mathrm{NaOH}$ Concentration}

The compressive strength was found initially increased and then decreased with increasing $\mathrm{NaOH}$ concentration as shown in Fig. 1.
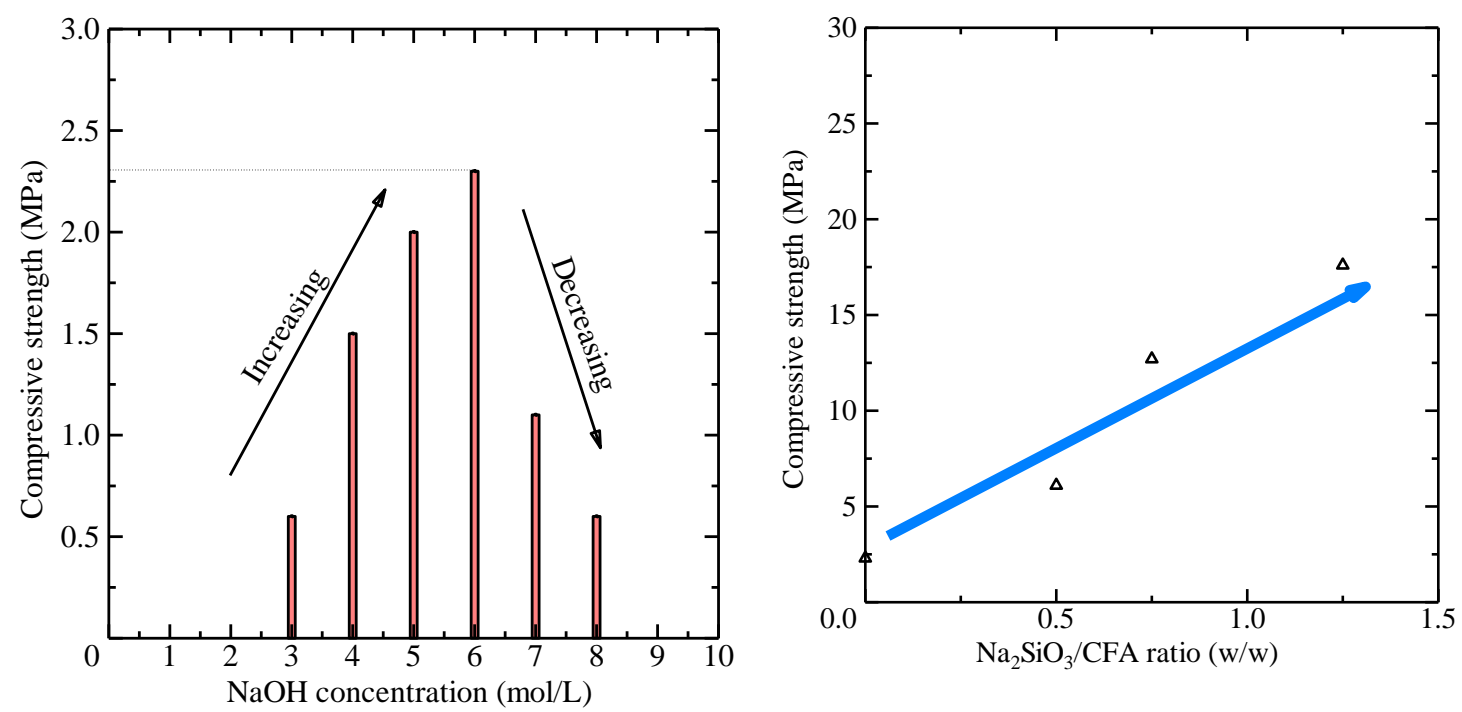

Figure 1 (left): Plot of compressive strength as a function of $\mathrm{NaOH}$ concentration. Figure 2 (right): Plot of compressive strength as a function of mass ratio of $\mathrm{Na} 2 \mathrm{SiO} 3$ to $\mathrm{CFA}$.

The increase in the compressive strength with increasing $\mathrm{NaOH}$ concentration is due to the fact that higher amounts of $\mathrm{OH}$ - ions facilitate the dissolution of silicate and aluminate species, which promote the 
polymerization 11 . However, if a very high alkaline environment (>30 Mol. \%) is used, the connectivity of silicate anions may be reduced resulting thus in poor polymerization12. Furthermore, excess $\mathrm{NaOH}$ forms sodium carbonate by atmospheric carbon13. Due to these reasons, the excess $\mathrm{NaOH}$ concentration causes decrease in the compressive strength of geopolymers.

\section{Compressive strength and amount of $\mathrm{Na2SiO3}$}

The compressive strength was found increasing with increasing mass ratio of $\mathrm{Na} 2 \mathrm{SiO} 3$ to CFA as shown in Fig. 2. This is because at high concentration of silicates, stronger ion-pair formation is expected, which results in the formation of longer chain silicate oligomers as well as Al-O-Si complexes i.e. geopolymer precursors 14 .

\section{Compressive strength and curing time}

The compressive strength was found increasing with increasing curing time as shown in Fig. 3.

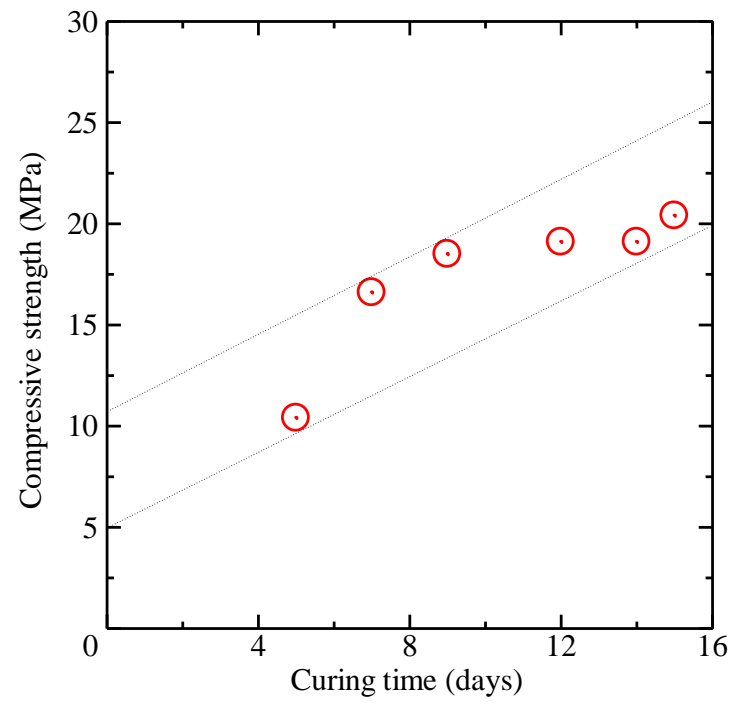

Figure 3: Plot of compressive strength as a function of curing time.

The data suggests that curing for longer period of time at low temperature is preferable for synthesis of geopolymers of higher compressive strengths. This is because the water present in geopolymers and its subsequent removal by evaporation plays a major role in obtaining a crack-free geopolymer. Thus rapid drying during curing should be avoided, whereas curing at a lower temperature is preferable 15 .

\section{Conclusions}

Hence geopolymers of better compressive strengths were synthesized from CFA waste by varying $\mathrm{NaOH}$ concentration, amount of $\mathrm{Na} 2 \mathrm{SiO} 3$ and curing time. The compressive strength was found initially increased and then decreased with increasing $\mathrm{NaOH}$ concentration. The maximum compressive strength of $2.3 \mathrm{M} \mathrm{Pa}$ was obtained with CFA treated with $6 \mathrm{M} \mathrm{NaOH}$ solution. Furthermore, the strength was found increasing with increasing $\mathrm{Na} 2 \mathrm{SiO} 3$ to CFA mass ratio and curing time. The maximum compressive strength of $17.6 \mathrm{MPa}$ was obtained with $\mathrm{Na} 2 \mathrm{SiO} 3$ to CFA mass ratio of 1.25 . It was possible to increase compressive strength up to $20.3 \mathrm{MPa}$ with increasing curing time suggesting that curing for longer period of time at low temperature is preferable for synthesis of geopolymers of higher compressive strengths. 
J. Nepal Chem. Soc., vol. 30, 2012

\section{References}

1. J.F. Meyers, P. Raman, and S.K. Bernadette, Federal Highway Administration, Report No. FHWA-IP-76-16, Washington DC, 1976.

2. J. Davidovits, Geopolymers: Chemistry and Applications, Institut Geopolymer, Paris, 2008.

3. C. Shi, and A. Fernández-Jiménez, J. Hazard. Mater., 2006, 137, 1656.

4. P. Duxson, J.L. Provis, G.C. Lukey and J.S.J. van Deventer, Cem. Concr. Res., 2007, 37, 1590.

5. J.G.S. van Jaarsveld, J.S.J. van Deventer and L. Lorenzen, Miner. Eng., 1997, 10, 659.

6. J.S.J. van Deventer, J. Mater. Sci., 2007, 42, 2917.

7. J. Davidovits, Proc. World Congress Geopolymer, Saint Quentin, France, 9-15, 2005.

8. E. Alvarez-Ayuso, X. Querol, F. Plana, A. Alastuey, N. Moreno, M. Izquierdo, O. Font, T. Moreno, S. Diez, E. Vazquez, and M. Barra, J. Hazard. Mater., 2008, 154, 175.

9. P. Chindaprasirt, T. Chareerat and V. Sirivivatnanon, Cem. Concr. Comp., 2007, 29, 224.

10 S. Detphan, and P. Chindaprasirt, Int'1 J. Miner. Metall. Mater., 2009, 16, 720.

11. K. Komnitsas and D. Zaharaki, Miner. Eng., 2007, 20, 1261.

12. P.S. Singh, T. Bastow, and M. Trigg, J. Mater. Sci., 2005, 40, 3951.

13. V.F.F. Barbosa, K.J.D. MacKenzie, and C. Thaumaturgo, Int'l J. Inorg. Mater., 2000, 2, 309.

14. A.V. McCormick, A.T. Bell and C.J. and Radke, J. Phys. Chem., 1989, 93, 1741.

15. D.S. Perera, O. Uchida, E.R. Vance and K.S. Finnie, J. Mater. Sci., 2007, 42, 3099. 